Jurnal Indonesia Sosial Teknologi: p-ISSN: 2723 - 6609

e-ISSN : 2745-5254

Vol. 2, No. 5 Mei 2021

\title{
ANALISIS MANAJEMEN RISIKO YANG MEMPENGARUHI KONTRAKTOR PADA PELAKSANAAN PROYEK JALAN DAN GEDUNG DI KABUPATEN MALINAU-KALIMANTAN UTARA
}

\author{
Hero Anda Gulindo \\ Magister Teknik Sipil, Program Pascasarjana, Universitas Atma Jaya Yogyakarta \\ Email: andagulindo@gmail.com
}

\section{Abstract}

In the construction industry, which has various types of projects with volumes to be worked on, as well as complex and complex methods of implementation that occur in the field, there must be various types of risks that affect the implementation of construction. These risk factors arise from various sources, and vary both in the likelihood of occurrence, the magnitude of the impact or impact. Contractors as construction implementers generally face risk factors that can hinder project success and of course will affect the performance of the contractors themselves, so that they can compete in the world of construction. This study aims to determine the risks that have an impact and the types of risks that very often occur on the performance of contractors in the implementation of road infrastructure projects and building projects in the district. Malinau, and knowing whether there are differences in impacts and types of risks that often occur in road infrastructure projects and building construction projects. This study uses a questionnaire method to collect the necessary data. The questionnaire was distributed to contractor companies located in Malinau District (North Kalimantan). The analytical method used is the mean, standard deviation and T test.From the analysis of the mean and standard deviation, we can find out the results of the impact and the types of risks that often occur which have the most influence on the implementation of building and road projects. In the results of the T-test analysis regarding the statement between building construction project and road project respondents, it is found that there is no significant similarity or significant difference in the impacts and risks that often occur between the implementation of building and road construction projects, a significant value $>0.05$, which means that there are similarities between the impact of risks and risks that often occur in the implementation of road and building infrastructure projects.

Keyword: Risk Management; Contractors; Buildings and Roads

\begin{abstract}
Abstrak
Dalam industri konstruksi yang memiliki beragam jenis proyek dengan besaran volume yang harus dikerjakan, serta rumit dan kompleksnya metode pelaksanaan yang terjadi di lapangan, pasti memiliki beragam jenis risiko yang berpengaruh dalam pelaksanaan konstruksi. Faktor risiko ini timbul dari berbagai sumber, serta bervariasi baik dalam kemungkinan terjadinya, besarnya pengaruh atau dampak yang ditimbulkan. Kontraktor sebagai pihak pelaksana konstruksi pada umumnya
\end{abstract}


akan menghadapi faktor-faktor risiko yang dapat menghambat kesuksesan proyek dan tentunya akan berpengaruh terhadap kinerja kontraktor itu sendiri, agar tetap dapat bersaing dalam dunia konstruksi. Penelitian ini bertujuan untuk mengetahui risiko yang memiliki dampak dan jenis-jenis risiko yang sangat sering terjadi terhadap kinerja kontraktor pada pelaksanaan Proyek infrastruktur Jalan dan proyek bangunan Gedung di Kab. Malinau, dan mengetahui ada tidaknya perbedaan dampak dan jenis risiko yang sering terjadi diproyek infrastruktur jalan dengan proyek bangunan Gedung. Penelitian ini menggunakan metode kuesioner untuk mengumpulkan data yang diperlukan. Kuesioner disebarkan kepada perusahaanperusahaan kontraktor yang berada di Kab Malinau (Kalimantan Utara). Metode analisis yang digunakan adalah mean, standar deviasi dan Uji T. Dari hasil analisis mean dan standar deviasi kita dapat mengetahui hasil dampak dan jenis-jenis risiko yang sering terjadi mana yang paling berpengaruh pada pelaksanaan proyek Gedung maupun proyek jalan. Pada hasil analisis uji-T mengenai peryataan antara responden proyek konstruksi Gedung dan proyek jalan, didapatkan kesamaan atau tidak terdapat perbedaan yang cukup signifikan pada dampak dan risiko yang sering terjadi antara pelaksanaan proyek konstruksi Gedung dan jalan, nilai signifikan > 0.05 yang berarti terdapat persamaan antara dampak risiko dan risiko yang sering terjadi pada pelaksanaan proyek infrastruktur jalan dan bangunan Gedung.

Kata kunci: Manajemen Risiko; kontraktor; Gedung dan Jalan

\section{Pendahuluan}

Indonesia merupakan salah satu negara yang sangat berkembang di mana banyak sekali proses pembangunan yang sedang dilaksanakan, pembangunan yang cukup signifikan terjadi pada pembangunan di bidang konstruksi. Salah satu tujuan usaha jasa konstruksi adalah mencari keuntungan, namun pada setiap kegiatan usaha jasa konstruksi akan selalu muncul dua hal yang berdampingan (Halomoan, 2020). Dua hal tersebut yaitu adanya peluang memperoleh keuntungan dan risiko menderita kerugian, baik secara langsung maupun tidak langsung tidak sedikit usaha jasa konstruksi yang mengalami kegagalan maupun kerugian (Suparno et al., 2019). Hal ini berarti semakin baik pengelolaan risiko, maka semakin kecil risiko yang akan dihadapi oleh perusahaan jasa konstruksi. Risiko yang terjadi pada proyek dapat berpengaruh buruk pada sasaran proyek yaitu jadwal, biaya/anggaran dan mutu,serta sekaligus merupakan kendala dalam pelaksanaan proyek (Mulyanto, 2012). Risiko proyek yang terkait dengan anggaran sering mengakibatkan terjadinya pembengkakan anggaran (cost overrun), sehingga mengakibatkan kerugian bagi kontraktor. Sedangkan risiko proyek yang terkait dengan jadwal, mengakibatkan keterlambatan penyelesaian proyek konstruksi, tentu ini berakibat kerugian bagi kontraktor maupun pemilik proyek. Pada sisi lain risiko proyek yang terkait dengan mutu sering meng-akibatkan kegagalan konstruksi, yang berakibat pada kerugian bagi kontraktor (Sariguna, 2011).Guna menghindari risiko-risiko tersebut seorang proyek manager harus mampu melakukan pengelolaan risiko-risiko sehingga tidak berakibat fatal pada pencapaian sasaran proyek (Serpella et al., 2014). Risikorisiko pada proyek konstruksi dapat menimpa semua pihak yang terkait (Flanagan, 
2012). Pemilik proyek (owner) bisa tertimpa risiko terkait investasi/keuangan, kontraktor bisa tertimpa risiko-risiko pelaksanaan konstruksi, pemasok bisa tertimpa risiko material/komponen yang dipasok, dan bank penyandang dana bisa tertimpa risiko kredit macet. Guna meminimalisasi konsekuensi buruk yang mungkin muncul, risiko harus didefinisikan dalam bentuk suatu rencana atau proses yang reaktif (Aningrum, 2012).

Risiko-risiko pada proyek konstruksi dapat menimpa semua pihak yang terkait (Flanagan, 2012) . Pemilik proyek (owner) bisa tertimpa risiko terkait investasi/keuangan, kontraktor bisa tertimpa risiko-risiko pelaksanaan konstruksi, pemasok bisa tertimpa risiko material/komponen yang dipasok, dan bank penyandang dana bisa tertimpa risiko kredit macet. Guna meminimalisasi konsekuensi buruk yang mungkin muncul, risiko harus didefinisikan dalam bentuk suatu rencana atau proses yang reaktif (Husen, 2010).

Sebuah kontrak kontruksi yang baik tentu saja mendistribusikan risiko-risiko dalam proses pelaksanaan pekerjaan konstruksi kepada pihak-pihak yang dapat menanggung potensi risiko teresebut (Hansen, 2015).

Tujuan dari penelitian ini adalah (1) Mengetahui risiko yang memiliki dampak besar terhadap kontraktor pada pelaksanaan Proyek Jalan dan Bangunan gedung. (2) Mengetahui jenis-jenis risiko yang sangat sering terjadi terhadap kontraktor pada pelaksanaan Proyek Jalan dan Proyek Bangunan gedung. (3) Mengetahui ada tidaknya perbedaan dampak dan jenis risiko yang sering terjadi diproyek jalan dengan proyek bangunan gedung.

\section{Metode Penelitian}

Penelitian tentang Manajemen Risiko Yang Mempengaruhi Kontraktor Pada Pelaksanaan Proyek jalan dan Gedung di kabupaten Malinau dilakukan dengan studi literatur yang dilanjutkan dengan Metode pengumpulan data pada penelitian ini dilakukan dengan penyebaran kuesioner interaktif secara langsung. Kuesioner berisi pernyataan, pertanyaan tertulis serta pilihan jawaban kepada para responden yang menjadi sampel penelitian. Dalam pengumpulan data, penulis membagi menjadi 2 (dua) macam data, yaitu:

a. Data primer, pada penelitian ini data primer meliputi data yang di peroleh dari penyebaran kuisoner. Dalam kuisoner terdapat sejumlah pertanyaan yang mengacu pada tujuan yang diharapkan penulis. Data yang dikumpulkan melalui kuisoner ini adalah ke 40 kontraktor yang dibagi diantara nya 20 oleh kontraktor proyek jalan dan 20 oleh kontraktor bangunan gedung.

b. Data sekunder, Data sekunder diperoleh dengan mengacu pada hasil penelitian sebelumnya yang mendekati konsep atau proses pengambilan keputusan dan juga sistem pengelolahan datanya. Selain itu juga melihat beberapa referensi dari buku atau jurnal yang ada. 


\section{Analisis data}

1. Analisis mean

Metode dengan analisis rata-rata (mean) bertujuan untuk menentukan nilai ratarata dari data yang diperoleh dari pengumpulan data, digunakan untuk menghitung rata-rata skoring jawaban kuisoner.

2. Analisa Standard Deviation

Dalam statistika dan probabilitas, standar deviasi digunakan untuk mengukur bagaimana nilai-nilai suatu data tersebar. Semakin kecil standar deviasi sebuah data, semakin tidak bervariasi data tersebut. Sebaliknya, semakin besar standar deviasi sebuah data, semakin bervariasi data tersebut.

3. Analisis Uji T (indenpendent-sample test)

Uji $\mathrm{T}$ ini dilakukan agar mengetahui adanya perbedaan mengenai dampak dan resiko yang sering terjadi pada pelaksanaan proyek jalan dan proyek kontruksi bangunan gedung. Analisis ini dengan menggunakan indenpendent- T test pada software SPSS 21. Dimana akan dilihat beberapa signifikan beda rata-rata dua kelompok tersebut. Analisis ini dihitung dengan memakai perbandingan antara sig (2-tailed) dengan ketelitian ( $\alpha$ ) 0,05. Dalam penelitian ini analisis korelasi menggunakan bantuan program komputer SPSS 21.

Sebelum sampai kepada Independet Samples T Test akan dilakukan Levene's Test, untuk melihat apakah kedua kelompok memiliki variansi yang sama atau tidak. Kesimpulan dari uji ini diambil dengan melihat sig, dengan derajat ketelitian $\alpha=0,05$ adalah sebagai berikut :

a. Bila sig $<\alpha$ maka Ho ditolak, hal ini berarti kedua variasi (ragam) tidak sama.

b. Bila sig $>\alpha$ maka Ho diterima, hal ini berarti kedua variasi (ragam) sama. Kemudian kesimpulan dari analisis ini diambil dengan melihat sig (2tailed), dengan derajat ketelitian $\alpha=0,05$. Hasil dari uji T ini ada dua yakni :

a. Bila sig (2tailed) $<\alpha$ maka Ho ditolak, hal ini berarti terdapat perbedaan yang cukup signifikan antara dampak risiko dan risiko yang sering terjadi pada pelaksanaan proyek infrastruktur jalan dan bangunan gedung

b. Bila sig (2tailed) $>\alpha$ maka Ho diterima, hal ini berarti tidak ada perbedaan yang cukup signifikan antara dampak risiko dan risiko yang sering terjadi pada pelaksanaan proyek infrastruktur jalan dan bangunan gedung

\section{Hasil dan Pembahasan}

\section{Analisis Data Secara Keseluruhan}

Analisis ini dilakukan secara keseluruhan terhadap bagian-bagian pernyataan yang meliputi risiko alam, risiko desain, risiko logistik, risiko keuangan, risiko hukum dan peraturan, risiko politik, risiko pelaksanaan konstruksi dan risiko lingkungan. Analisis ini dilakukan agar peneliti bisa mengetahui bagian pernyataan yang paling berpengaruh terhadap Penyebab manajemen risiko terhadap kontraktor jalan dan gedung di Kabupaten Malinau (Kalimantan Utara ) (Rustam, 2020). 
Analisis Manajemen Risiko Yang Mempengaruhi Kontraktor pada Pelaksanaan Proyek Jalan dan Gedung di Kabupaten Malinau-Kalimantan Utara

Tabel 1. Pengaruh manajemen risiko terhadap kontraktor secara keseluruhan pada proyek Jalan.

\begin{tabular}{|c|c|c|c|c|c|}
\hline No & Pernyataan & $\begin{array}{c}\text { Dampak dan } \\
\text { frekuensi }\end{array}$ & mean & $\begin{array}{l}\text { Standar } \\
\text { deviasi }\end{array}$ & rank \\
\hline \multirow[t]{2}{*}{1} & \multirow[b]{2}{*}{ Alam } & dampak & 8.30 & 2.53 & 6 \\
\hline & & frekuensi & 6.75 & 1.89 & 6 \\
\hline \multirow[t]{2}{*}{2} & \multirow[b]{2}{*}{ Desain } & dampak & 13.40 & 1.76 & 5 \\
\hline & & frekuensi & 10.55 & 1.70 & 5 \\
\hline \multirow[t]{2}{*}{3} & \multirow[b]{2}{*}{ Logistik } & dampak & 24.0 & 5.14 & 3 \\
\hline & & frekuensi & 20.65 & 2.34 & 3 \\
\hline \multirow[t]{2}{*}{4} & \multirow[b]{2}{*}{ Keuangan } & dampak & 29.40 & 3.51 & 2 \\
\hline & & frekuensi & 24.01 & 3.68 & 2 \\
\hline \multirow[t]{2}{*}{5} & \multirow{2}{*}{$\begin{array}{c}\text { Hukum dan } \\
\text { Peraturan }\end{array}$} & dampak & 17.70 & 2.81 & 4 \\
\hline & & frekuensi & 12.05 & 1.82 & 4 \\
\hline \multirow[t]{2}{*}{6} & \multirow{2}{*}{ Politik } & dampak & 5.65 & 1.72 & 8 \\
\hline & & frekuensi & 4.60 & 1.04 & 8 \\
\hline \multirow[t]{2}{*}{7} & \multirow{2}{*}{$\begin{array}{c}\text { Pelaksanaan } \\
\text { Konstruksi }\end{array}$} & dampak & 45.55 & 6.02 & 1 \\
\hline & & frekuensi & 39.40 & 4.86 & 1 \\
\hline \multirow[t]{2}{*}{8} & \multirow[b]{2}{*}{ Lingkungan } & dampak & 7.71 & 2.84 & 7 \\
\hline & & frekuensi & 7.10 & 2.12 & 7 \\
\hline
\end{tabular}

Berdasarkan hasil analisis diperoleh kesimpulan bahwa dampak dan frekuensi manajemen risiko terhadap kontraktor secara keseluruhan pada proyek Jalan adalah risiko pelaksanaan konstruksi.Dengan mean dampak risiko 45.55 sedangkan frekuensi ( risiko sering terjadi ) 39.40 (Wena, 2015)

Tabel 2. Pengaruh manajemen risiko terhadap kontraktor secara keseluruhan pada proyek Gedung

\begin{tabular}{cccccc}
\hline No & Pernyataan & $\begin{array}{c}\text { dampak dan } \\
\text { frekuensi }\end{array}$ & mean & $\begin{array}{c}\text { Standar } \\
\text { deviasi }\end{array}$ & rank \\
\hline 1 & \multirow{2}{*}{ Alam } & dampak & 9.45 & 2.03 & 6 \\
\cline { 3 - 6 } & \multirow{2}{*}{ Desain } & frekuensi & 6.70 & 2.15 & 6 \\
\hline \multirow{2}{*}{2} & dampak & 13.90 & 1.83 & 5 \\
\cline { 3 - 6 } & \multirow{2}{*}{ Logistik } & frekuensi & 11.75 & 1.80 & 5 \\
\cline { 3 - 6 } & \multirow{2}{*}{ Keuangan } & dampak & 25.35 & 5.65 & 3 \\
\hline \multirow{2}{*}{4} & frekuensi & 22.60 & 3.06 & 3 \\
\cline { 3 - 6 } & \multirow{2}{*}{ Hukum dan } & dampak & 29.05 & 5.80 & 2 \\
\hline
\end{tabular}




\begin{tabular}{cccccc}
\hline & Peraturan & frekuensi & 12.60 & 2.09 & 4 \\
\hline 6 & \multirow{2}{*}{ Politik } & dampak & 6.50 & 1.97 & 8 \\
\cline { 3 - 6 } & \multirow{2}{*}{$\begin{array}{c}\text { Pelaksanaan } \\
\text { Konstruksi }\end{array}$} & frekuensi & 4.50 & 1.43 & 8 \\
\cline { 3 - 6 } & dampak & 47.10 & 8.75 & 1 \\
\hline \multirow{2}{*}{8} & frekuensi & 38.25 & 5.10 & 1 \\
& \multirow{2}{*}{ Lingkungan } & dampak & 8.10 & 2.82 & 7 \\
\cline { 3 - 6 } & & frekuensi & 7.85 & 1.80 & 7 \\
\hline
\end{tabular}

Berdasarkan hasil analisis diperoleh kesimpulan bahwa dampak dan frekuensi manajemen risiko terhadap kontraktor secara keseluruhan pada proyek Gedung adalah risiko pelaksanaan konstruksi.Dengan mean dampak risiko 47.55 sedangkan mean frekuensi ( risiko sering terjadi ) 38.25

Perbandingan dampak risiko dan risiko yang sering terjadi pada pelaksanaan proyek jalan dan proyek Gedung.

Analisis ini mengkaji persepsi responden dalam menilai jenis-jenis risiko dalam pelaksanaan proyek infrastruktur jalan dan proyek gedung Dari data kuesioner yang disebarkan kepada 40 responden, terdapat 8 pertanyaan, diantaranya : Alam (3 pertanyaan), desain (4 pertanyaan), logistik ( 7 pertanyaan), keuangan ( 8 pertanyaan), hukum dan peraturan (5 pertanyaan), politik (3 pertanyaan), pelaksanaan konstruksi (14 pertanyaan), lingkungan (3 pertanyaan). Dari ke 8 Risiko tersebut dicari nilai rata-rata (mean) dari proyek konstruksi gedung dan proyek jalan. Kemudian dilakukan analisis persamaan berdasarkan nilai mean.

Hasil penelitian diolah dengan menggunakan indenpendent- sample test pada software SPSS 21. Dimana akan dilihat beberapa signifikan beda rata-rata dari dua kelompok tersebut.

Dampak risiko.

Tabel 3. Hasil uji T (Independet sample Test) untuk perhitungan perbedaan persepsi terhadap dampak risiko dari proyek konstruksi Gedung dan proyek konstruksi jalan

\begin{tabular}{ccccccc}
\hline & & \multicolumn{2}{c}{$\begin{array}{c}\text { Levene's Test } \\
\text { for Equality of } \\
\text { Variances }\end{array}$} & \multicolumn{2}{c}{ t-test for Equality of Means } \\
\cline { 3 - 7 } alam & F & Sig. & t & df & $\begin{array}{c}\text { Sig (2- } \\
\text { tailed) }\end{array}$ \\
\hline \multirow{3}{*}{} & $\begin{array}{c}\text { Equal } \\
\text { variances } \\
\text { assumed }\end{array}$ & 1.89 & .177 & -1.581 & 38 & 0.448 \\
\cline { 2 - 7 } & $\begin{array}{c}\text { Equal } \\
\text { variances }\end{array}$ & & & -1.581 & 36,321 & 0.449 \\
\hline
\end{tabular}




\begin{tabular}{|c|c|c|c|c|c|c|}
\hline & not assumed & & & & & \\
\hline \multirow{2}{*}{ desain } & $\begin{array}{c}\text { Equal } \\
\text { variances } \\
\text { assumed } \\
\end{array}$ & .134 & .716 & -0.880 & 38 & 0.384 \\
\hline & $\begin{array}{c}\text { Equal } \\
\text { variances } \\
\text { not assumed }\end{array}$ & & & -0.880 & 37.937 & 0.384 \\
\hline \multirow{2}{*}{ logistik } & $\begin{array}{c}\text { Equal } \\
\text { variances } \\
\text { assumed }\end{array}$ & .040 & .842 & -0.790 & 38 & 0.435 \\
\hline & $\begin{array}{c}\text { Equal } \\
\text { variances } \\
\text { not assumed }\end{array}$ & & & -0.790 & 37.653 & 0.435 \\
\hline \multirow{2}{*}{ keuangan } & $\begin{array}{c}\text { Equal } \\
\text { variances } \\
\text { assumed }\end{array}$ & 1.800 & .188 & .123 & 38 & .818 \\
\hline & $\begin{array}{c}\text { Equal } \\
\text { variances } \\
\text { not assumed }\end{array}$ & & & .123 & 31.332 & .819 \\
\hline \multirow{2}{*}{$\begin{array}{c}\text { Hukum dan } \\
\text { peraturan }\end{array}$} & $\begin{array}{c}\text { Equal } \\
\text { variances } \\
\text { assumed }\end{array}$ & .094 & .760 & -.726 & 38 & .472 \\
\hline & $\begin{array}{c}\text { Equal } \\
\text { variances } \\
\text { not assumed }\end{array}$ & & & -.726 & 35.619 & .472 \\
\hline \multirow{2}{*}{ politik } & $\begin{array}{c}\text { Equal } \\
\text { variances } \\
\text { assumed } \\
\end{array}$ & .014 & .905 & -1.456 & 38 & .154 \\
\hline & $\begin{array}{c}\text { Equal } \\
\text { variances } \\
\text { not assumed }\end{array}$ & & & -1.456 & 37.397 & .154 \\
\hline \multirow{2}{*}{$\begin{array}{c}\text { pelaksanaan } \\
\text { konstruksi }\end{array}$} & $\begin{array}{c}\text { Equal } \\
\text { variances } \\
\text { assumed }\end{array}$ & .746 & .393 & -.652 & 38 & .518 \\
\hline & $\begin{array}{c}\text { Equal } \\
\text { variances } \\
\text { not assumed }\end{array}$ & & & -.652 & 33.693 & .519 \\
\hline \multirow{2}{*}{ lingkungan } & $\begin{array}{c}\text { Equal } \\
\text { variances } \\
\text { assumed }\end{array}$ & .023 & .881 & -.446 & 38 & .658 \\
\hline & $\begin{array}{c}\text { Equal } \\
\text { variances } \\
\text { not assumed }\end{array}$ & & & -.446 & 37.998 & .658 \\
\hline
\end{tabular}

Dari hasil analisis uji-T (indenpendent-sample test) mengenai persepsi antara proyek konstruksi gedung dan proyek jalan terhadap dampak risiko pada alam, desain, logistik, keuangan, hukum dan peraturan, politik, pelaksanaan konstruksi dan lingkungan didapatkan kesamaan persepsi antara proyek konstruksi gedung dan proyek jalan. dapat dilihat pada kolom Levene's Test nilai signifikansi adalah $>0,05$, maka $\mathrm{H}_{0}$ 
diterima dan dapat disimpulkan bahwa varian data dampak risiko kedua jenis proyek adalah sama, maka digunakan Equal Variances assumed untuk selanjutnya dilakukan analisis Uji T. Berdasarkan uji T, Terlihat pada kolom t-test for Equality of Means, pada baris Equal variances assumed, didapatkan nilai signifikansi 2-tailed adalah > 0.05 sehingga $\mathrm{H}_{0}$ diterima, sehingga tidak terdapat perbedaan yang cukup signifikan antara dampak risiko pelaksanaan proyek jalan dan proyek Gedung Di Kabupaten Malinau.

Frekuensi risiko

Tabel 4. Hasil uji T (Independet sample Test ) untuk perhitungan perbedaan persepsi terhadap frekuensi risiko dari proyek konstruksi Gedung dan proyek konstruksi jalan

\begin{tabular}{|c|c|c|c|c|c|c|}
\hline & & \multicolumn{2}{|c|}{$\begin{array}{l}\text { Levene's Test } \\
\text { for Equality of } \\
\text { Variances }\end{array}$} & \multicolumn{3}{|c|}{ t-test for Equality of Means } \\
\hline & & $\mathrm{F}$ & Sig. & $\mathrm{t}$ & $\mathrm{df}$ & $\begin{array}{l}\text { Sig (2- } \\
\text { tailed) }\end{array}$ \\
\hline \multirow[b]{2}{*}{ alam } & $\begin{array}{c}\text { Equal } \\
\text { variances } \\
\text { assumed }\end{array}$ & 1.538 & .223 & .078 & 38 & .938 \\
\hline & $\begin{array}{c}\text { Equal } \\
\text { variances } \\
\text { not } \\
\text { assumed }\end{array}$ & & & .078 & 37.358 & .938 \\
\hline \multirow[b]{2}{*}{ desain } & $\begin{array}{c}\text { Equal } \\
\text { variances } \\
\text { assumed }\end{array}$ & .158 & 693 & -2.184 & 38 & .035 \\
\hline & $\begin{array}{c}\text { Equal } \\
\text { variances } \\
\text { not } \\
\text { assumed } \\
\end{array}$ & & & -2.184 & 37.778 & .035 \\
\hline \multirow[b]{2}{*}{ logistik } & $\begin{array}{c}\text { Equal } \\
\text { variances } \\
\text { assumed }\end{array}$ & 2.391 & .130 & -2.258 & 38 & .030 \\
\hline & $\begin{array}{c}\text { Equal } \\
\text { variances } \\
\text { not } \\
\text { assumed }\end{array}$ & & & -2.258 & 5.558 & .030 \\
\hline \multirow[b]{2}{*}{ keuangan } & $\begin{array}{c}\text { Equal } \\
\text { variances } \\
\text { assumed }\end{array}$ & 1.316 & .258 & -.184 & 38 & .855 \\
\hline & $\begin{array}{c}\text { Equal } \\
\text { variances } \\
\text { not } \\
\text { assumed }\end{array}$ & & & -.184 & 35.855 & .855 \\
\hline $\begin{array}{l}\text { Hukum } \\
\text { dan } \\
\text { peraturan }\end{array}$ & $\begin{array}{c}\text { Equal } \\
\text { variances } \\
\text { assumed }\end{array}$ & .317 & .577 & -.888 & 38 & .380 \\
\hline
\end{tabular}




\begin{tabular}{|c|c|c|c|c|c|c|}
\hline & $\begin{array}{c}\text { Equal } \\
\text { variances } \\
\text { not } \\
\text { assumed }\end{array}$ & & & -.888 & 37.308 & .380 \\
\hline \multirow[b]{2}{*}{ politik } & $\begin{array}{c}\text { Equal } \\
\text { variances } \\
\text { assumed }\end{array}$ & .014 & .905 & -1.456 & 38 & .154 \\
\hline & $\begin{array}{c}\text { Equal } \\
\text { variances } \\
\text { not } \\
\text { assumed }\end{array}$ & & & -1.456 & 37.397 & .154 \\
\hline \multirow{2}{*}{$\begin{array}{l}\text { pelaksana } \\
\text { an } \\
\text { konstruksi }\end{array}$} & $\begin{array}{c}\text { Equal } \\
\text { variances } \\
\text { assumed }\end{array}$ & .004 & .950 & -.391 & 38 & .698 \\
\hline & $\begin{array}{c}\text { Equal } \\
\text { variances } \\
\text { not } \\
\text { assumed }\end{array}$ & & & -.391 & 37.993 & .698 \\
\hline \multirow{2}{*}{$\begin{array}{c}\text { lingkunga } \\
n\end{array}$} & $\begin{array}{c}\text { Equal } \\
\text { variances } \\
\text { assumed }\end{array}$ & .356 & .554 & -1.209 & 38 & .234 \\
\hline & $\begin{array}{c}\text { Equal } \\
\text { variances } \\
\text { not } \\
\text { assumed }\end{array}$ & & & -1.209 & 36.902 & .235 \\
\hline
\end{tabular}

Dari hasil analisis uji-T (indenpendent-sample test) mengenai persepsi antara proyek konstruksi gedung dan proyek jalan terhadap Frekuensi risiko pada alam, desain, logistik, keuangan, hukum dan peraturan, politik, pelaksanaan konstruksi dan lingkungan didapatkan kesamaan persepsi antara proyek konstruksi gedung dan proyek jalan. dapat dilihat pada kolom Levene's Test nilai signifikansi adalah $>0,05$, maka $\mathrm{H}_{0}$ diterima dan dapat disimpulkan bahwa varian data dampak risiko kedua jenis proyek adalah sama, maka digunakan Equal Variances assumed untuk selanjutnya dilakukan analisis Uji T. Berdasarkan uji T, Terlihat pada kolom $t$-test for Equality of Means, pada baris Equal variances assumed, didapatkan nilai signifikansi 2-tailed adalah > 0.05 sehingga $\mathrm{H}_{0}$ diterima, sehingga tidak terdapat perbedaan yang cukup signifikan antara Frekuensi risiko pelaksanaan proyek jalan dan proyek Gedung Di Kabupaten Malinau.

\section{Kesimpulan}

Berdasarkan hasil dan pembahasan tentang Analisis Manajemen Resiko Yang Mempengaruhi Kontraktor Pada Pelaksanaan Proyek Jalan dan Proyek Gedung, di Malinau-Kalimantan Utara, diperoleh beberapa kesimpulan antara lain :

1. Risiko yang memiliki dampak besar terhadap kontraktor pada pelaksanaan Proyek Jalan dan gedung di Kab Malinau adalah Pelaksanaan Konstruksi.

2. Risiko yang yang sangat sering terjadi terhadap kontraktor pada pelaksanaan Proyek Jalan dan gedung di Kab Malinau adalah pelaksanaan Konstruksi 
3. Berikut merupakan pengujian uji $\mathrm{T}$ untuk mengetahui apakah ada nya perbedaan frekuensi risiko yang sering terjadi dan dampak risiko pada pelaksanaan proyek infrastruktur jalan dengan proyek Gedung di Kab. Malinau :

a. Pada Risiko Alam : dari hasil pengujian uji T untuk dampak dan frekuensi risiko alam tidak terdapat perbedaan yang cukup signifikan antara pelaksanaan proyek infrastruktur jalan dan proyek Gedung di Kab malinau

b. Pada risiko Desain : dari hasil pengujian uji $\mathrm{T}$ untuk dampak dan frekuensi Risiko Desain menunjukan tidak terdapat perbedaan yang cukup signifikan antara pelaksanaan proyek infrastruktur jalan dan proyek Gedung di Kab malinau.

c. Pada risiko Logistik : dari hasil pengujian uji T untuk dampak dan frekuensi Risiko Logistik menunjukan tidak terdapat perbedaan yang cukup signifikan antara pelaksanaan proyek infrastruktur jalan dan proyek Gedung di Kab malinau.

d. Pada risiko Keuangan : dari hasil pengujian uji T untuk dampak dan frekuensi Risiko Keuangan menunjukan tidak terdapat perbedaan yang cukup signifikan antara pelaksanaan proyek infrastruktur jalan dan proyek Gedung di Kab malinau.

e. Pada risiko Hukum dan Peraturan : dari hasil pengujian uji $\mathrm{T}$ untuk dampak dan frekuensi Risiko Hukum dan Peraturan menunjukan tidak terdapat perbedaan yang cukup signifikan antara pelaksanaan proyek infrastruktur jalan dan proyek Gedung di Kab malinau.

f. Pada risiko Politik : dari hasil pengujian uji T untuk dampak dan frekuensi Risiko Politik menunjukan tidak terdapat perbedaan yang cukup signifikan antara pelaksanaan proyek infrastruktur jalan dan proyek Gedung di Kab malinau.

g. Pada kategori Pelaksanaan Kontruksi : dari hasil pengujian uji T untuk dampak dan frekuensi Risiko Pelaksanaan Kontruksi menunjukan tidak terdapat perbedaan yang cukup signifikan antara pelaksanaan proyek infrastruktur jalan dan proyek Gedung di Kab malinau

h. Pada kategori Lingkungan : dari hasil pengujian uji $\mathrm{T}$ untuk dampak dan frekuensi Risiko Lingkungan menunjukan tidak terdapat perbedaan yang cukup signifikan antara pelaksanaan proyek infrastruktur jalan dan proyek Gedung di Kab malinau. 
Analisis Manajemen Risiko Yang Mempengaruhi Kontraktor pada Pelaksanaan Proyek Jalan dan Gedung di Kabupaten Malinau-Kalimantan Utara

\section{Bibliography}

Aningrum, B. S. (2012). Identifikasi Dan Analisis Risiko dalam Masa Pemeliharaan Proyek pada Proyek Konstruksi Di Kota Surakarta.

Flanagan, R. (2012). Managing Risk For Anuncertain Future A Project Management perspective. In School of Construction Management and Engineering The University of Reading $U K$.

Halomoan, K. (2020). Konstruksi Kebijakan Publik Peran Badan Usaha Koperasi Bidang Jasa Konstruksi Berbasis Nilai Keadilan. Universitas Islam Sultan Agung Semarang.

Hansen, S. (2015). Manajemen kontrak konstruksi. Gramedia Pustaka Utama.

Husen, A. (2010). Manajemen Proyek: Perencanaan. Penjadwalan, Dan Pengendalian Proyek, Penerbit Andi Yogyakarta.

Mulyanto, B. (2012). Manajemen Risiko Dalam Pelaksanaan Proyek Konstruksi. BANGUNAN: Teori, Praktek, Penelitian, Dan Pengajaran Teknik Bangunan, 16(1).

Rustam, B. R. (2020). Manajemen Risiko prinsip, penerapan, dan penelitian.

Sariguna. (2011). Faktor Risiko Terhadap Kinerja Kontraktor. http://www.ilerning.com

Serpella, A. F., Ferrada, X., Howard, R., \& Rubio, L. (2014). Risk management in construction projects: a knowledge-based approach. Procedia-Social and Behavioral Sciences, 119, 653-662.

Suparno, S., Revantoro, N. B., \& Wena, M. (2019). Implemantasi Manajemen Risko Dalam Pelaksanaan Proyek Konstruksi Bagi Para Konsultan Dan Kontraktor. Jurnal Graha Pengabdian, 1(2), 86-92.

Wena, M. (2015). Manajemen risiko dalam proyek konstruksi. Jurnal Bangunan, 20(112). 